\title{
Determining the Leeway Drift Characteristics of Tropical Pacific Island Craft
}

\author{
Ben A Brushett ${ }^{\mathrm{a}, \mathrm{b}}$, Arthur A Allen ${ }^{\mathrm{c}}$, Victoria C Futch ${ }^{\mathrm{d}}$, Brian A King ${ }^{\mathrm{b}}$, \& Charles J Lemckert ${ }^{\mathrm{a}}$
}

\author{
${ }^{a}$ Griffith School of Engineering \\ Griffith University \\ Gold Coast, QLD 4222 \\ Australia \\ ben.brushett@student.griffith.edu.au \\ c.lemckert@griffith.edu.au
}

\author{
${ }^{b}$ Asia Pacific ASA \\ PO Box 1679 \\ Surfers Paradise, \\ QLD 4217
}

Australia

bking@apasa.com.au

\author{
${ }^{c}$ U.S. Coast Guard \\ Office of Search and \\ Rescue (CG-SAR-1) \\ U.S. Coast Guard \\ International Ice Patrol \\ 1 Chelsea Street \\ New London, CT 06320 \\ United States of America
}

Arthur.A.Allen@uscg.mil

\author{
${ }^{d}$ U.S. Coast Guard \\ U.S. Coast Guard Academy \\ Science Department (dsm) \\ 27 Mohegan Avenue \\ New London, CT 06320 \\ United States of America \\ Victoria.C.Futch@uscga.edu
}

\begin{abstract}
:
An accurate understanding of the leeway drift characteristics of drifting objects is required to effectively forecast the drift of persons, vessels or objects lost at sea, and to generate efficient search areas to maximise the probability of successfully locating those missing. Presently, the most effective method for calculating the leeway drift characteristics of an object or vessel is to empirically derive the leeway coefficients of that object through field studies. The main goal of the studies is to measure how the object drifts in relation to the surface currents due to the wind and wave action upon it. This paper outlines the determination of downwind and crosswind leeway coefficients for three small craft common to Pacific island communities for which no accurate leeway coefficients exist. These craft were: a 19 foot $(5.8 \mathrm{~m})$ fibreglass skiff (known locally as pangas, fibres, or banana boats); a 20 foot $(5.97 \mathrm{~m})$ fibreglass outrigger canoe; and a 2-person sit down personal water craft (PWC). Due to the vast distances between pacific islands and the remoteness of these locations it can be several days until a search can be mounted to rescue those lost at sea, hence it is paramount that an accurate description of the drift of these tropical pacific craft is available for use in search and rescue (SAR) drift models, to define appropriate search areas. This study successfully derived the leeway coefficients required for each of these three craft. The leeway speed of the outrigger canoe and PWC, both with one person on board (POB) equivalent loading, were calculated to be $2.40 \%$ and $4.24 \%$ of the wind speed respectively. The leeway speed of the skiff was found to range between $7.71 \%$ and $4.40 \%$ of the wind speed for equivalent loading between 1 POB and 13 POB.

The results of these field tests have subsequently been implemented into search and rescue models by several SAR organisations worldwide. These results show that the findings herein have the potential to both increase the likelihood of finding persons adrift at sea alive, as well as reducing search costs through more effective drift prediction and efficient search area formulation.
\end{abstract}

Keywords: Panga, Outrigger Canoe, Personal Water Craft, Search and Rescue

Regional Index Terms: Tropical Western Pacific, Federated States of Micronesia (FSM), Guam 


\section{Introduction}

Several key elements are required to successfully predict the drift of a person or object at sea, these include search and rescue (SAR) drift forecast models, input wind and current forecast data and the drift object's leeway drift coefficients. Maritime search and rescue (SAR) drift forecast models are used to numerically model the drift of an object at sea; however these models are only as effective as the input data provided. Both accurate external forcing data (winds and currents) and a well-defined representation of how the object may drift due to the external forces upon it are essential model inputs. The forces acting upon a drift object include those from wind, waves and currents. Prior studies have shown that the drift of an object due to wave action (forcing) only becomes significant once the drift objects have a length scale greater than that of the wavelength [1], and as the drift objects investigated herein have a length less than the wavelength, effects due to wave forcing may be disregarded. Wind and current forcing may be provided through a number of means, including near real time observations and more commonly, numerical forecast models. As the object drifts with the currents, it is exposed to the effects of the wind and waves. The combined effect upon the drift of an object due to wind and waves is described as the "leeway" of the object.

The leeway of an object varies from object to object and therefore a new set of leeway coefficients is required for each drift object to accurately determine their leeway drift characteristics. Without the correct leeway coefficients, it is impossible to accurately forecast how that object may drift. Leeway field tests are currently the most common and most accurate method for determining the leeway coefficients of a drift object. A standard approach to the leeway field tests is outlined by Breivik et al. [2]. The leeway study was carried out at three locations within the tropical North Pacific Ocean during the months of May and June 2012 (refer to Figure 1). The initial 5-day drift of the skiffs (and multiple single-day drifts of the PWC and outrigger canoe) commenced approximately $15 \mathrm{~km}$ off the western coast of Chuuk Lagoon in the Federated States of Micronesia (FSM). The next study location (one single-day drift of all craft) took place approximately $20 \mathrm{~km}$ to the north of Puluwat Atoll (westernmost land features of Chuuk State, FSM). The final study (single-day, all craft) took place approximately $10 \mathrm{~km}$ to the west of Apra Harbour, Guam. All drifts were undertaken in deep water where the dominant current forcing was attributable to the westward flowing North Equatorial Current (NEC).

The total drift of an object at sea can be summarized by the three equations below (adapted from Hackett et al. [3]). Equation 1 shows that the total drift is a summation of the drift due to currents (relative to the earth) plus the drift due to leeway (slip relative to the ambient currents). The drift due to currents is a result of the combination of surface currents (derived from Ekman drift, baroclinic motion, tidal currents and inertial currents), as well as drift due to wave induced currents or Stokes drift (Equation 2). Leeway drift is the sum of the drift due to the winds acting on the object plus the drift due to the wave forces acting on the object (Equation $3)$. 


$$
D_{T}=D_{C}+D_{L}
$$

Where:

$$
\begin{aligned}
& D_{T}=\text { Total Object Drift } \\
& D_{C}=\text { Drift Due to Current forces (relative to the earth) } \\
& D_{L}=\text { Drift Due to Leeway (relative to the currents) }
\end{aligned}
$$

And

$$
D_{C}=D_{S c}+D_{S d}
$$

Where:

$D_{C}=$ Drift due to Currents

$D_{S c}=$ Drift due to Surface currents

$D_{S d}=$ Drift due to Stokes drift

And

$$
D_{L}=D_{W i}+D_{W a}
$$

Where:

$$
\begin{aligned}
& D_{L}=\text { Drift Due to Leeway } \\
& D_{W i}=\text { Drift due to Wind forces } \\
& D_{W a}=\text { Drift due to Wave forces }
\end{aligned}
$$

The effect of Stokes drift may be present for the drift of an object on the water surface, in two forms. The first is Stokes drift due to wind generated waves, and the second is the Stokes drift due to swell. The wind generated wave-induced Stokes drift predominately acts in a downwind direction (the same direction as the wind) however the swell-induced Stokes drift acts in the direction of the swell, which is not necessarily the same direction as the wind generated waves, and hence may not be in the downwind direction. As it was not possible to determine the swell direction in this study and due to the minimal swell encountered, any Stokes drift was assumed to be a result of wind generated waves only, and act in the downwind direction. The swell-induced Stokes drift may become an important factor in higher energetic areas with larger swell sizes. Once the drift due to surface currents has been subtracted from the total drift, the empirically derived leeway drift of the object cannot distinguish between the downwind leeway drift effects and the downwind Stokes drift effects on the drift of the object, and therefore the effects that Stokes drift may have on the drift of the object are included in the regression of the leeway of the object. As a result of this, Breivik et al. [2] recommend that for small craft it is most practical to express leeway as a function of the wind only.

Breivik and Allen [4] suggest that the drift due to wave forces may be ignored for small craft whose length is less than that of the wavelength, as the drift due to wave forcing may only become significant once the object's length is similar to the wavelength (e.g. large vessels).

In summary, as the lengths of the craft used in this study were significantly less than the wavelength, the effects of wave forces were assumed to be negligible, and as the wind generated wave-induced Stokes drift was 
accounted for in the leeway coefficients derived for the objects, the total drift of the objects was calculated as a sum of the drift due to the surface currents and the drift due to the wind.

The definition of leeway has evolved over time, with each iteration becoming more rigorous and less ambiguous. The most recent definition of leeway is listed by Breivik et al. ( [2] and [1]) where it is defined as:

\section{"Leeway is the motion of the object induced by wind (10 $\mathrm{m}$ reference height) and waves relative to} the ambient current (between 0.3 and $1.0 \mathrm{~m}$ depth)".

This definition allows the SAR responder to use standard $10 \mathrm{~m}$ reference height model forecast winds and the surface layer of current forecast models or currents measured by HF radar.

There are two methods of describing the leeway of a drifting object. Both methods refer to the speed of the drift of the object when compared to the $10 \mathrm{~m}$ reference height wind speed. The first method refers to the object's leeway speed and divergence angle referenced to the down wind direction and speed. The second method decomposes the leeway speed and divergence angle into downwind leeway (DWL) and crosswind leeway (CWL) vectors. The former method, utilising leeway speed and divergence angle, has historically been used for manual drift planning, however Allen [5] noted that when using numerical model solutions for drift planning, the leeway divergence angle can cause the solution to become unstable at low wind speeds when wind direction fluctuates. As a result, the latter method using DWL and CWL is the preferred method for numerical SAR models as it does not suffer the same shortfall and remains numerically stable, even at low wind speeds.

The leeway coefficients can be calculated through either a constrained or non-constrained linear regression with the $10 \mathrm{~m}$ wind speed. The constrained through zero regression implies that the leeway will be zero when there is no wind, whilst the non-constrained linear regression implies that there may still be some residual leeway drift of the object by forcing other than winds when winds are zero. Utilising the constrained through zero regression provides the most stable numerical solution for modelling search object trajectories, whereas numerical models utilising the unconstrained regression may incur difficulties if zero wind speeds are encountered (due to having no wind direction in which to apply the leeway component). This is generally not a problem as zero wind speeds rarely occur, however there are several approaches which can be utilised by numerical models to circumvent this potential issue, which include: a) carrying forward the wind direction from the previous model time step to calculate the residual trajectory when there is zero wind speed; b) removing the residual trajectory for cases where there is zero wind speed; or c) no modification to the model code, as conditions with zero wind speeds are infrequent. Each approach has their merits and drawbacks, so it is important to implement the approach which best suits the particular application.

Leeway field tests have been carried out in one form or another since the first recorded results by Pingree [6] who carried out studies on the drift of Navy life rafts in World War II. A thorough review of the various leeway experiments / field tests conducted up until 1999, as well as a summary of the leeway speed and divergence angle of 63 drift objects is contained within Allen and Plourde [7]. A further review of leeway divergence was published by Allen [5] who provided the CWL and DWL coefficients for the 63 objects defined in Allen and 
Plourde [7]. Since then, there have been further leeway field tests undertaken by various organisations and countries worldwide including the United States of America, Canada, Norway and France.

A semi analytical numerical approach to calculating the leeway of shipping containers at various immersion levels was presented by Daniel et al. [8]. This was a unique approach as thus far, the majority of other leeway studies utilised an empirical approach to determining the leeway coefficients. Daniel et al. [8] presented three case studies of previous shipping incidents which occurred in 1993, 1996 and 1997 where shipping containers were adrift at sea, and a case study comparing the results from a previous leeway field test carried out on 20' shipping containers off Brittany (France) in 1991 - 1992. Leeway field tests were carried out in 2008 as a joint venture between Norway, France and the US. The studies were undertaken in Norway, and investigated the leeway of; a 1:1/3 sized model of a 40' shipping container, a WWII mine, and a 220 L (550-gallon) oil drum. Another joint venture between Norway, France and the US saw further leeway field tests were carried out in 2009 in Norway [9]. This study successfully collected leeway drift data for; a full sized 20' shipping container, a $4.5 \mathrm{~m}$ open aluminium skiff, Sunfish sailing dinghy, a Person in Water (PIW) in the deceased position and additional data was collected for the WWII mine. All objects were appropriately instrumented to follow the direct method of collecting leeway data. Breivik et al. [10] combined the shipping container results from the 2008 and 2009 leeway field tests in Norway and compared them to the semi analytical leeway model of shipping containers presented by Daniel et al. [8]. Further, results were extrapolated to account for different immersion levels of shipping containers (immersion level is one uncertainty faced by SAR responders when modelling drifting objects).

The frequency in which the drift object changes direction from left of downwind (positive cross wind) to right of downwind (negative cross wind) is known as the jibing frequency. Jibing frequency is measured as a percentage per hour over the duration that an object may be adrift. Allen [5] introduced the jibing frequency concept in terms of defining the search areas for drift objects. A drifting object may jibe suddenly, with an instantaneous change in CWL sign, or it may occur gradually over time which is more difficult to determine. It may be possible to numerically identify a gradual jibe from the drift track and wind data however if there is a limited amount of drift data it may be deemed sufficient to visually interpret a progressive vector diagram of the drift run to identify the jibing events.

The purpose of this study was to undertake a series of leeway field studies to determine the leeway coefficients of three water craft common to tropical Pacific islands, whose leeway coefficients were previously unknown. These three craft included a 5.8m (19') fibreglass skiff, a 5.97m (19.6') fibreglass outrigger canoe, and a 2person sit down personal water craft (PWC). The outcomes of this study allows SAR planners to more accurately forecast the drift of the three objects, and plan search efforts more effectively. Improved definition of search areas increase the likelihood of finding the missing persons or craft quicker, and hence reduced search times increase the probability of finding the missing persons and increase their chances of survival [11]. In addition, search efforts and the related high costs involved with maritime searches may be reduced. 


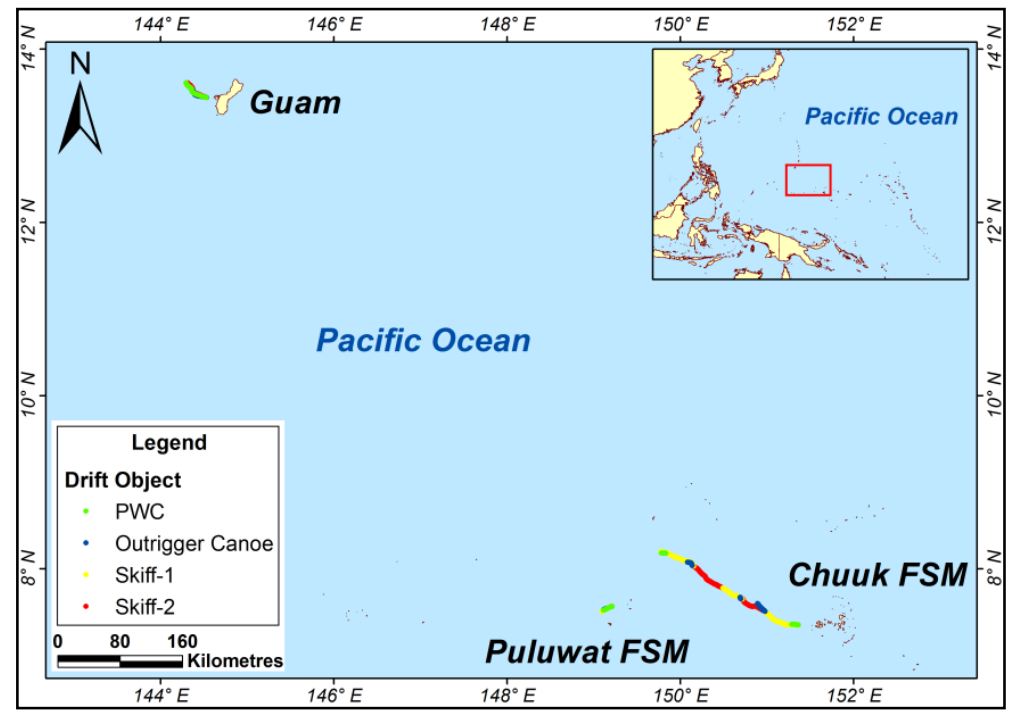

Figure 1. Location map showing the tracks of the leeway drift objects (coloured lines) at the three locations studied; Chuuk (FSM), Puluwat (FSM) and Guam.

\section{Methodology}

A standard methodology for determining the leeway of floating objects was set out by Breivik et al. [2] to ensure subsequent field tests to gather leeway data on other objects of interest could be conducted in a consistent manner. This allows for interchangeable data which is able to be implemented into the various numerical SAR models currently in use by various SAR organisations worldwide. An overview of some maritime SAR models and their use with ocean current forecast data for predicting the drift of objects or craft is included in Davidson et al., [12]. Further information in regards to these SAR models include; the United States Coast Guard SAROPS (Search and Rescue Optimal Planning System) [13]; the Leeway model used by the Norwegian Coast Guard [4]; the SARMAP model used by Maritime New Zealand and the Australian Maritime Safety Authority [14, 15]; the Canadian Search and Rescue Planning program (CANSARP) utilised by the Canadian Coast Guard [16]; and the French MOTHY (Modèle Océanique de Transport d'Hydrocarbures) system run by Météo-France [17].

There are two methods for determining the leeway of an object, the direct method and the indirect method [2]. The direct method uses a current meter directly attached or tethered to the object that is being studied, as opposed to the indirect method which estimates the currents from a nearby vessel or object to infer the leeway slip of the study object. The indirect method is not as accurate as the direct method, however it may be necessary when the study objects are too small to either fit or tether a current meter to (for example, medical waste). The preferred method for determining the leeway of an object is the direct method.

In this standardised methodology, Breivik et al. [2] identified four categories of leeway objects which are categorised based on their size and ability to carry various instrumentation, as outlined in Table 1 below. 
Table 1. Leeway object categories

\begin{tabular}{|c|c|c|c|}
\hline Category & Object Size & Leeway Method & Instrumentation \\
\hline 1 & Small (e.g. EPIRB, Floating debris) & Indirect & Location device only \\
\hline 2 & Small to Medium (e.g. PIW, PWC) & Direct & Location device plus current meter \\
\hline 3 & Medium (e.g. Life raft, Skiff) & Direct & $\begin{array}{l}\text { Location device, current meter and } \\
\text { weather station }\end{array}$ \\
\hline 4 & $\begin{array}{l}\text { Large (e.g. Large boat, Shipping } \\
\text { container ) }\end{array}$ & Direct & $\begin{array}{l}\text { Location device, current meter and } \\
\text { weather station }\end{array}$ \\
\hline
\end{tabular}

The three objects studied in this field test all fell within categories 2 and 3. The PWC and the Outrigger canoe were both deemed too small to adequately accommodate weather stations, and therefore fell within category 2 , whilst the skiffs were outfitted with weather stations, and hence fell within category 3 . The direct method was used for calculating the leeway for all three craft in this test as each was able to carry a current meter for direct measurements of the surface currents.

A full description of the background, model setup and results for this study is contained within the technical document Allen et al. [18].

\subsection{Drift Objects}

Several craft are common to the tropical Pacific island inhabitants, which include the 19 or 23 foot fibreglass skiff, also commonly known to locals as Pangas, Fibres (due to their fibreglass construction), or Banana boats (due to their curved appearance). Outrigger canoes and PWC are also common.

\subsubsection{Skiff:}

The Search and Rescue Exercise (SAREX) conducted by the USCG during the leeway field tests required a continuous 5-day drift of a 19 foot $(5.8 \mathrm{~m})$ fibreglass skiff. Two identical skiffs were used in a leapfrog deployment to safeguard against unforseen technical issues and a potential loss of data. The two identical 19 foot fibreglass skiffs (Skiff-One and Skiff-Two, refer to Figure 2a) were outfitted with the necessary instrumentation including current meters, weather stations, GPS (Global Positioning System) Iridium transmitters and flashing lights. Skiff-One was deployed first, for approximately 24 hours before Skiff-Two was deployed nearby to the location of Skiff-One at 24 hours. Once Skiff-Two was drifting in clear water, Skiff-One was then recovered and once on board the support vessel, the data from the current meter and weather station was downloaded (to ensure the data had recorded correctly and all sensors were working correctly). This deployment system also had the added benefit of being able to check the condition of the skiffs (e.g. if they had filled with rain water from overnight storms) and to ensure all batteries for the instrumentation were fully charged between deployments. This 24 hour leap frog deployment schedule ensured that any faults with the instrumentation, would only result in a maximum of 24 hours of data lost.

\subsubsection{Outrigger Canoe:}

A variety of different outrigger canoes are common to the tropical Pacific islands, varying from small 1-person craft, up to larger 20 to 30 foot versions, which can be fitted with a sail for longer distance journeys. Some outrigger canoes are constructed in the traditional ways from timber, whilst others are constructed of fibreglass. 
The outrigger canoe selected for this study was a $5.97 \mathrm{~m}$ fibreglass design which was designed to carry 1 to 2 persons (Figure 2b).

\subsubsection{Personal Water Craft:}

The PWC used in these leeway drift tests was an older style $2.7 \mathrm{~m}$ Yamaha 2-person sit down type (Figure 2c). PWCs are commonly used for recreational use in coastal and near shore waterways. Other sizes and style PWCs also include one person stand up style, as well as 3 and 4 person sit down styles. The PWC used in this study had the engine removed and a downward facing ADCP (Acoustic Doppler Current Profiler) mounted through the centre of the hull.
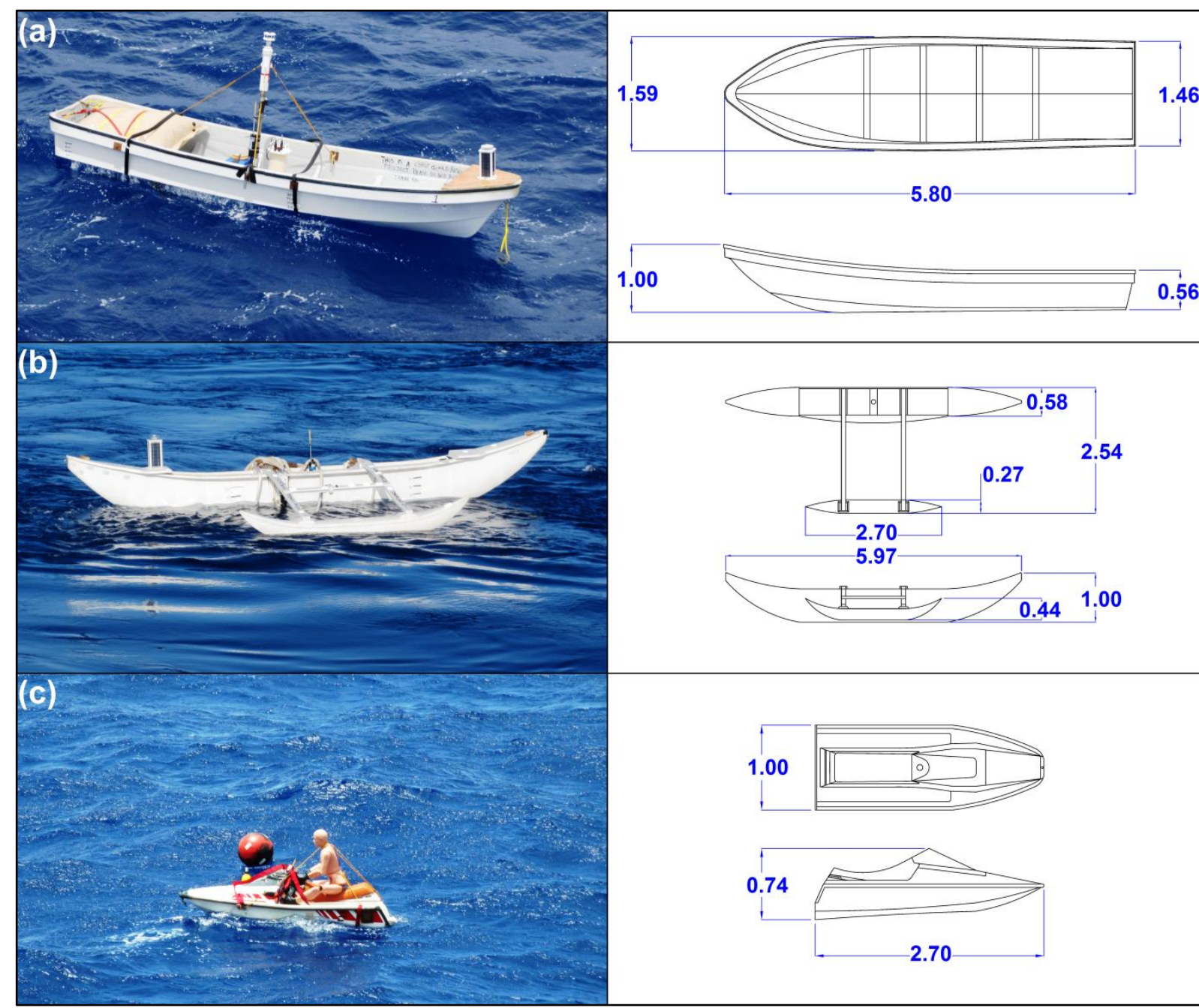

Figure 2. Craft tested; (a) 5.8m Skiff, (b) 5.97m Outrigger Canoe, and (c) Personal Water Craft. Line drawings on the right side show the dimensions (in metres) of the corresponding drift objects tested.

\subsection{Instrumentation}

Each of the drift objects were outfitted with various instrumentation; including GPS beacons with Iridium satellite transmitters, ADCP current meters, and weather stations, as well as RDF (Radio Direction Finding) beacons and strobe lights. The following section outlines the instrumentation specifics and data sampling periods utilised on each of the drift objects studied. Table 2 gives a brief overview of the instruments fitted to the drift objects. 
Table 2. Instrumentation installed on drift objects

\begin{tabular}{|c|c|c|c|c|}
\hline Drift Object & Current Meter & Weather Station & GPS & Other \\
\hline Skiff-One & $\begin{array}{l}\text { Nortek ADCP - } \\
\text { AquaDopp } 2 \mathrm{MHz}\end{array}$ & $\begin{array}{c}\text { Coastal } \\
\text { Environmental } \\
\text { System - } \\
\text { WeatherPak } 2000\end{array}$ & $\begin{array}{c}\text { Clearwater } \\
\text { Iridium Beacon }\end{array}$ & $\begin{array}{l}\text { Carmanah Marine Lantern - } \\
\text { M704-5 }\end{array}$ \\
\hline Skiff-Two & $\begin{array}{l}\text { Nortek ADCP - } \\
\text { AquaDopp } 2 \mathrm{MHz}\end{array}$ & $\begin{array}{c}\text { Coastal } \\
\text { Environmental } \\
\text { System - } \\
\text { WeatherPak } 2000\end{array}$ & $\begin{array}{c}\text { Clearwater } \\
\text { Iridium Beacon }\end{array}$ & $\begin{array}{c}\text { Carmanah Marine Lantern - } \\
\text { M704-5 }\end{array}$ \\
\hline Outrigger Canoe & $\begin{array}{r}\text { Nortek ADCP - } \\
\text { Aquadopp } 2 \mathrm{MHz}\end{array}$ & -- & $\begin{array}{c}\text { Clearwater } \\
\text { Iridium Beacon }\end{array}$ & $\begin{array}{l}\text { NovaTech RDF Flasher } \\
\text { Beacon - RDF-700C1 }\end{array}$ \\
\hline PWC & $\begin{array}{c}\text { RDI ADCP - } \\
\text { Workhorse Monitor } \\
1228.8 \mathrm{kHz}\end{array}$ & -- & $\begin{array}{c}\text { Clearwater } \\
\text { Iridium Beacon }\end{array}$ & $\begin{array}{l}\text { NovaTech RDF Flasher } \\
\text { Beacon - RF-700C1 }\end{array}$ \\
\hline
\end{tabular}

\subsubsection{Location Devices}

Each of the craft was fitted with Clearwater Instrumentation GPS/Iridium transmitter beacons, each with a unique IMEI (International Mobile station Equipment Identification) number, which transmitted the location of each of the drift objects back to the Iridium receiver on board the USCGC Sequoia every 10 minutes (on the 10 minute mark) in near real time (approximately 30 to 45 seconds delay). This enabled the position and speed over ground to be recorded for each of the craft, as well as to facilitate the location and recovery of the craft at the end of each drift run. The skiffs were fitted with Carmanah Marine Lanterns (M704-5) to enable the skiffs to be seen at night or under low light and to aid in their recovery. These lanterns were essentially a solar powered flashing light, with a light sensor that switched them off during the day and on again at night. The outrigger canoe and the PWC were both fitted with NovaTech combination RDF flashing beacons. These devices were fitted with an RDF transmitter that also contained a flashing strobe light which automatically switched on when it was dark.

\subsubsection{Current meters}

Two different types of current meters were used in this study to measure the sea surface currents relative to the drift objects. The first was the Nortek AquaDopp $2 \mathrm{MHz}$ ADCP, which was fitted to each of the skiffs and the outrigger canoe. The second type of current meter used was an RDI Workhorse Monitor 1228.8 kHz ADCP, fitted to the PWC in a special gimbal setup to minimise tilt. Skiff-One and Skiff-Two each had their respective ADCP fitted to the transom, where the outboard engine would have been fixed. The outrigger canoe had the ADCP fitted to the side of the hull on the same side as the outrigger, slightly offset from amidships. It was positioned on the outrigger side of the hull to ensure it was not damaged during deployment and recovery.

The sampling frequency, sampling average, blanking distance, bin size, number of bins and head depth for the current meters are all listed for each of the four drift objects in Table 3. Data was averaged over the surface 6-8 bins (depending on the current meter), and one minute averages were adjusted to account for magnetic variation, and then rotated a further $180^{\circ}$ to account for leeway frame of reference. The one minute samples were then averaged to 10 minute samples as Breivik and Allen [4] established the maximum correlation of leeway occurred with zero lag at 10 minute samples. 
Table 3. Current meter specifics

\begin{tabular}{|c|c|c|c|c|c|c|c|}
\hline Drift Object & Current Meter & $\begin{array}{c}\text { Sampling } \\
\text { Frequency } \\
(\mathrm{Hz})\end{array}$ & $\begin{array}{c}\text { Sampling } \\
\text { Average } \\
\text { (min) }\end{array}$ & $\begin{array}{c}\text { Blanking } \\
\text { Distance } \\
(\mathrm{cm})\end{array}$ & $\begin{array}{l}\text { Bin Size } \\
(\mathrm{cm})\end{array}$ & $\begin{array}{l}\text { Number of } \\
\text { Bins Used }\end{array}$ & $\begin{array}{c}\text { Head } \\
\text { Depth }(\mathrm{cm})\end{array}$ \\
\hline $\begin{array}{l}\text { Skiff-One \& } \\
\text { Skiff-Two }\end{array}$ & $\begin{array}{c}\text { AquaDopp } 2 \mathrm{MHz} \\
\text { ADCP }\end{array}$ & 1.0 & $1 \& 10$ & 10 & 10 & 8 & $20-25$ \\
\hline $\begin{array}{l}\text { Outrigger } \\
\text { Canoe }\end{array}$ & $\begin{array}{c}\text { AquaDopp } 2 \mathrm{MHz} \\
\text { ADCP }\end{array}$ & 1.0 & $1 \& 10$ & 10 & 10 & 6 & $5-10$ \\
\hline PWC & $\begin{array}{c}\text { RDI Workhorse } \\
\text { Monitor } 1228.8 \mathrm{kHz}\end{array}$ & 1.0 & $1 \& 10$ & $50 \& 25^{\mathrm{a}}$ & $5 \& 10^{\mathrm{a}}$ & $6 \& 5^{\mathrm{a}}$ & 10 \\
\hline
\end{tabular}

${ }^{a}$ Initial PWC run had a blanking distance of $50 \mathrm{~cm}$ and $5 \mathrm{~cm}$ bin size ( $x 6$ bins), subsequent runs had a blanking distance of $25 \mathrm{~cm}$ and $10 \mathrm{~cm}$ bin size ( $x 5$ bins).

\subsubsection{Weather Stations}

A weather station was mounted to each of the skiffs, and was deployed in close proximity to the outrigger canoe and the PWC, as they were too small to directly mount a weather station to. Weather station measurements from the skiffs could then also be made available to the leeway regression calculations for the PWC and outrigger canoe as winds on the ocean are relatively consistent and do not fluctuate considerably over small distances, it is acceptable to use the winds measured on a nearby object [2]. The weather stations fitted to the skiffs were Coastal Environmental System WeatherPak 2000 units, each fitted with a Gill ultrasonic anemometer, which is an improvement over the older mechanical style anemometer as the ultrasonic versions do not have a dead band. Resolution of wind direction was $1^{\circ}$ with an accuracy of $\pm 3^{\circ}$. The minimum wind speed threshold for the anemometers was $0.01 \mathrm{~m} / \mathrm{s}$. The WeatherPaks also measured: wind gust, air temperature, GPS position, internal temperature and battery voltage. The unit fitted to Skiff-Two also contained a humidity sensor and a barometer. The barometer was used to correct the offset of the pressure sensor on the ADCP, which measured the depth of the ADCP in the water. All samples from the WeatherPaks were taken at a frequency of $1 \mathrm{~Hz}$, and then averaged over 10 minutes to align with the 10 minute averages of the current meters. The anemometer height was $1.79 \mathrm{~m}$ and $1.83 \mathrm{~m}$ above the waterline for Skiff-One and Skiff-Two respectively.

\subsection{Object Loading}

One of the many uncertainties faced with predicting the drift of an object at sea, is the state in which the object or craft is in. Objects will exhibit different drift characteristics depending on the loading to which they are subject. Drift objects/craft which are heavily loaded will sit lower in the water, thus increasing their cross sectional area exposed to currents, as well as decreasing the cross sectional area exposed to wind. This has the combined outcome of increasing the effects of currents whilst decreasing the effects of winds upon the drift of the object, hence reducing the magnitude of the leeway of the object. The reverse is also true, whereby a decrease in the loading of a drift object will increase the object's leeway, thus allowing it to follow the winds more and the currents less. To understand how the drift objects would drift under these differing loading circumstances it is important to test the object's leeway drift under varying loadings. Previous studies by Breivik et al. [10] and Daniel et al. [8] investigated how shipping containers drifted under differing immersion levels (which has the similar effect to differing loadings of the craft). 
The skiffs were tested under several different loadings, using sand bags as extra weight. The loadings were tested in terms of persons on board (POB) and included; 1 POB, 2 POB, 4 POB, and 13 POB equivalent loadings. In addition, sand bags were placed at the stern of the skiffs to simulate the weight of the standard 40hp outboard motor. As the PWC and Outrigger Canoe are smaller objects with limited carrying capacities, they were tested in one configuration - with 1 POB, which would be their most likely loading configuration.

\subsection{Data Processing}

The wind speeds measured on the skiffs were adjusted from their measurement height up to the standard $10 \mathrm{~m}$ reference height following Smith [19]. These wind speeds were then corrected by using the GPS positions to allow for the movement of the skiffs. The 10 minute samples of the winds and currents were matched in time, and the measured leeway was decomposed into the DWL and CWL components. The CWL was split into positive and negative depending on whether drift was to the left (negative) or right (positive) of the downwind direction. Additionally, a (-1) times the negative CWL coefficient was also calculated to enable both the positive and negative CWL values to be plotted on the same positive axis. A linear regression using a least squares best fit was carried out for the leeway speed, DWL and CWL, with each regressed against the wind speed (adjusted to $10 \mathrm{~m}$ height). This was repeated for both unconstrained and constrained through zero linear regressions. From the linear regression, the slope, $y$ intercept and $\mathrm{r}^{2}$ values were calculated, as well as the standard error term $\left(\mathrm{S}_{\mathrm{yx}}\right)$.

The nine leeway coefficients identified by Breivik and Allen [4] and Breivik et al. [2] are shown in Equations 4 to 6 below. Note these can be compressed to six coefficients for the constrained through zero regression, as the y intercept is zero. The subscripts refer to the vector components of leeway; DWL (d), Positive CWL (c+) and Negative CWL (c-)

$$
\begin{aligned}
& L_{d}=a_{d} W_{10}+b_{d}+E_{d} \\
& L_{c+}=a_{c+} W_{10}+b_{c+}+E_{c+} \\
& L_{c-}=a_{c-} W_{10}+b_{c-}+E_{c-}
\end{aligned}
$$

Where:

$L=$ Predicted leeway $(\mathrm{cm} / \mathrm{s})$ at a given value of $\mathrm{W}_{10}$ wind speed.

$a=$ Slope of the regression line through the data, to give leeway as $(\%)$ of $\mathrm{W}_{10}$ wind speed

$W_{10}=$ Wind speed at $10 \mathrm{~m}$ reference height

$b=\mathrm{Y}$ intercept or offset term for unconstrained regression

$E=$ additional error term

Progressive vector diagrams (PVD) were generated by plotting the leeway drift with respect to the downwind direction for each drift run. This allowed the jibing analysis to be undertaken, as the PVD allows the switches between positive and negative leeway over prolonged periods (several 10 minute time samples) to be readily identified (thus indicating a jibing event). 


\section{Results}

The drift tracks from the leeway field tests undertaken in the tropical Pacific ocean during May/June 2012 are shown in Figure 3 (Chuuk, FSM), Figure 4 (Puluwat atoll, FSM), and Figure 5 (Guam). A summary of each of the drift runs is provided in Table 4. The results from the analysis and linear regression of the leeway coefficients for each of the individual drift objects (skiff, outrigger canoe, and PWC) are shown in Table 5 to Table 8. For brevity only the linear regression plots for the leeway speed, DWL and CWL of the 2 POB skiff are shown (refer to Figure 6), whilst the full analysis of each of the drift objects (under all loadings tested) including the linear regression plots can be found in the leeway field test technical report [18]. The jibing frequency analysis for all drift objects follows and is shown in Table 9.

\subsection{Summary of the drift runs}

Table 4 below provides a summary of the drift runs and outlines the deployment times, retrieval times, duration of the run as well as the $10 \mathrm{~m}$ reference height wind speed range, and the locations for each of the individual leeway runs. It should be noted there were three runs that did not return usable data, these included PWC Run-2 (ADCP battery failed), PWC Run-4 (ADCP was tilted beyond tolerances in gimbals during deployment), and Skiff-One Run-5 (skiff was overloaded beyond the 6 POB loading which resulted in unsuccessful recovery).

Table 4. Summary of the drift runs

\begin{tabular}{|c|c|c|c|c|c|c|c|}
\hline Drift Object & $\begin{array}{c}\text { Run } \\
\#\end{array}$ & $\begin{array}{c}\text { POB } \\
\#\end{array}$ & $\begin{array}{c}\text { Deployment } \\
\text { Date Time } \\
\text { UTC }\end{array}$ & $\begin{array}{c}\text { Retrieval } \\
\text { Time Date } \\
\text { UTC }\end{array}$ & $\begin{array}{l}\text { Duration } \\
\text { hh:mm }\end{array}$ & $\begin{array}{c}10 \mathrm{~m} \text { Wind } \\
\text { Speed Range } \\
\mathrm{m} / \mathrm{s}\end{array}$ & Location \\
\hline Skiff-One & 1 & 2 & 28/5/2012 0:48 & $28 / 5 / 201223: 32$ & $22: 44$ & $2.0-9.1$ & Chuuk \\
\hline PWC & 1 & 0 & 28/5/2012 1:00 & 28/5/2012 6:02 & 05:02 & $4.8-9.1$ & Chuuk \\
\hline Canoe & 1 & 1 & 28/5/2012 23:06 & $29 / 5 / 20126: 20$ & $07: 14$ & $2.7-4.7$ & Chuuk \\
\hline PWC $^{b}$ & $z$ & $\theta$ & $28 / 5 / 201223: 19$ & 29/5/2012 6:00 & $06: 41$ & $\mathrm{n} / \mathrm{a}$ & Chuuk \\
\hline Skiff-Two & 1 & 2 & 28/5/2012 22:45 & $29 / 5 / 201222: 59$ & $24: 14$ & $2.7-9.3$ & Chuuk \\
\hline Skiff-One & 2 & 2 & 29/5/2012 23:30 & $30 / 5 / 2012$ 22:22 & $22: 52$ & $2.8-9.0$ & Chuuk \\
\hline Canoe & 2 & 1 & $30 / 5 / 20120: 28$ & 3/05/2012 5:52 & $05: 24$ & $2.8-6.2$ & Chuuk \\
\hline Skiff-Two & 2 & 2 & $30 / 5 / 201222: 14$ & $31 / 5 / 201223: 15$ & $25: 01$ & $2.9-11.9$ & Chuuk \\
\hline Canoe & 3 & 1 & $31 / 5 / 201222: 52$ & $1 / 5 / 20125: 46$ & $06: 54$ & $5.3-9.0$ & Chuuk \\
\hline Skiff-One & 3 & 2 & $31 / 5 / 201222: 32$ & 2/5/2012 2:26 & $27: 54$ & $5.3-9.1$ & Chuuk \\
\hline PWC & 3 & 1 & 1/6/2012 22:16 & 2/6/2012 2:05 & 03:49 & $6.9-8.4$ & Chuuk \\
\hline Skiff-One & 4 & 1 & 8/6/2012 21:17 & 9/6/2012 8:02 & $10: 45$ & $1.4-4.7$ & Puluwat \\
\hline Skiff-Two & 3 & 4 & 8/6/2012 21:11 & 9/6/2012 8:23 & $11: 12$ & $1.6-4.6$ & Puluwat \\
\hline Canoe & 4 & 1 & 8/6/2012 21:25 & 9/6/2012 8:55 & $11: 30$ & $1.6-4.6$ & Puluwat \\
\hline PWC $^{c}$ & 4 & 4 & $8 / 6 / 201221: 28$ & $9 / 6 / 20128: 36$ & 11:08 & $\mathrm{n} / \mathrm{a}$ & Puluwat \\
\hline Skiff-One ${ }^{\mathrm{d}}$ & 5 & 6 & $12 / 6 / 20120: 24$ & $12 / 6 / 20120: 41$ & $\theta: 17$ & $\mathrm{n} / \mathrm{a}$ & Guam \\
\hline Skiff-Two & 4 & 4 & 12/6/2012 0:19 & $12 / 6 / 201222: 12$ & $21: 53$ & $2.2-9.6$ & Guam \\
\hline Canoe & 5 & 1 & 12/6/2012 0:29 & $12 / 6 / 201223: 21$ & $22: 52$ & $2.2-9.6$ & Guam \\
\hline PWC & 5 & 1 & 12/6/2012 0:33 & $12 / 6 / 201222: 37$ & 22:04 & $2.2-9.6$ & Guam \\
\hline
\end{tabular}




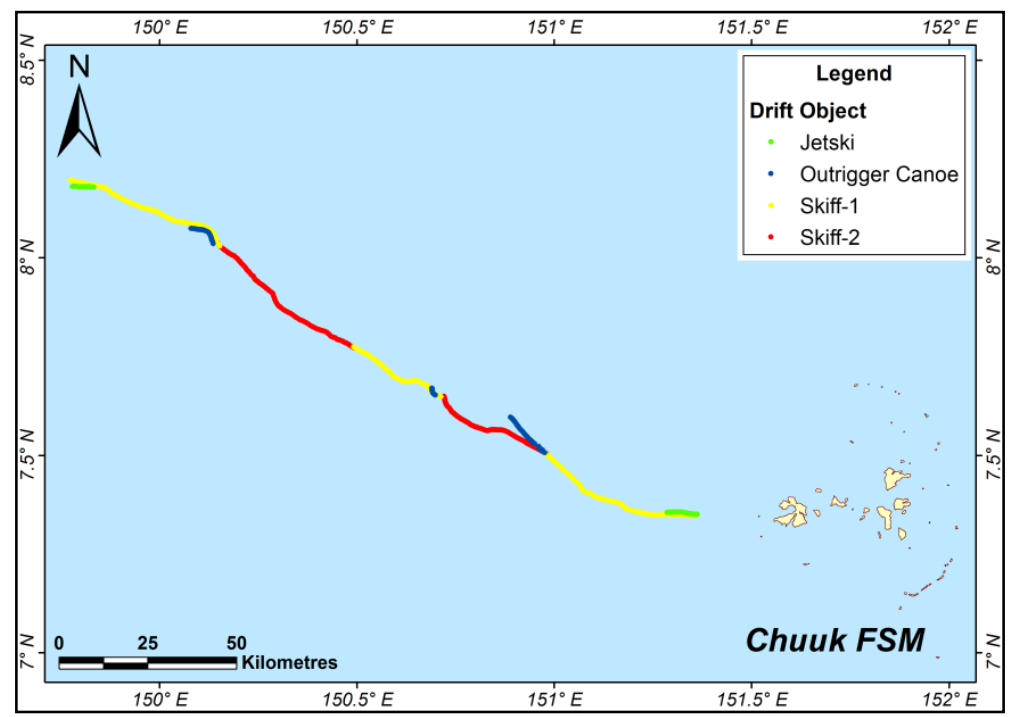

Figure 3. Chuuk drift runs: $28^{\text {th }}$ of May 2012 to $2^{\text {nd }}$ of June 2012

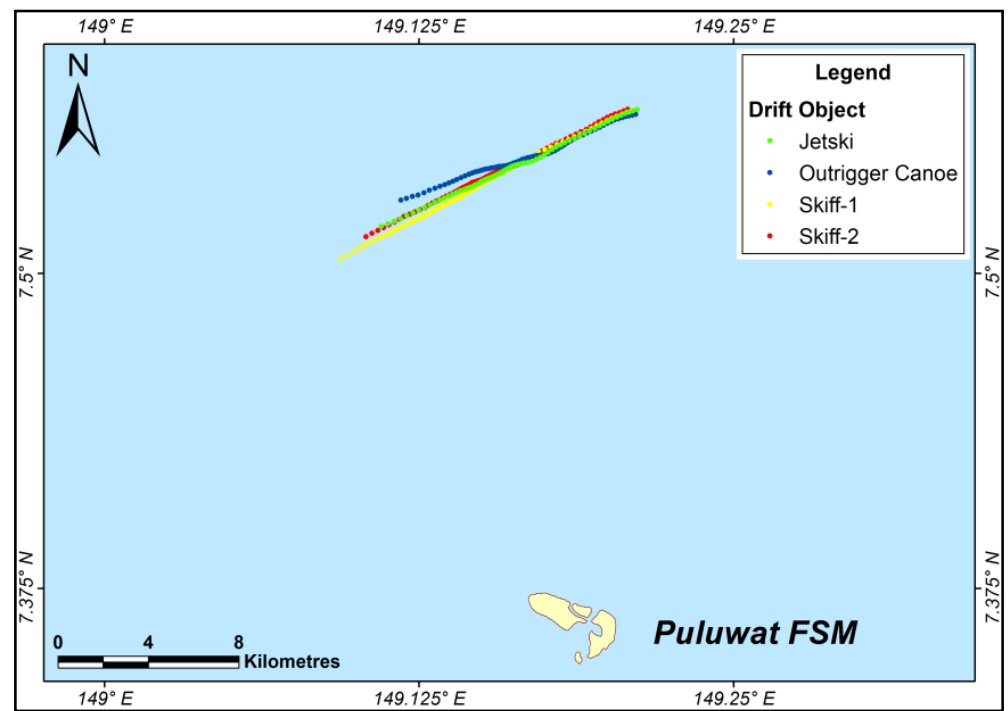

Figure 4. Puluwat drift runs: $8^{\text {th }}$ of June 2012 to $9^{\text {th }}$ of June 2012

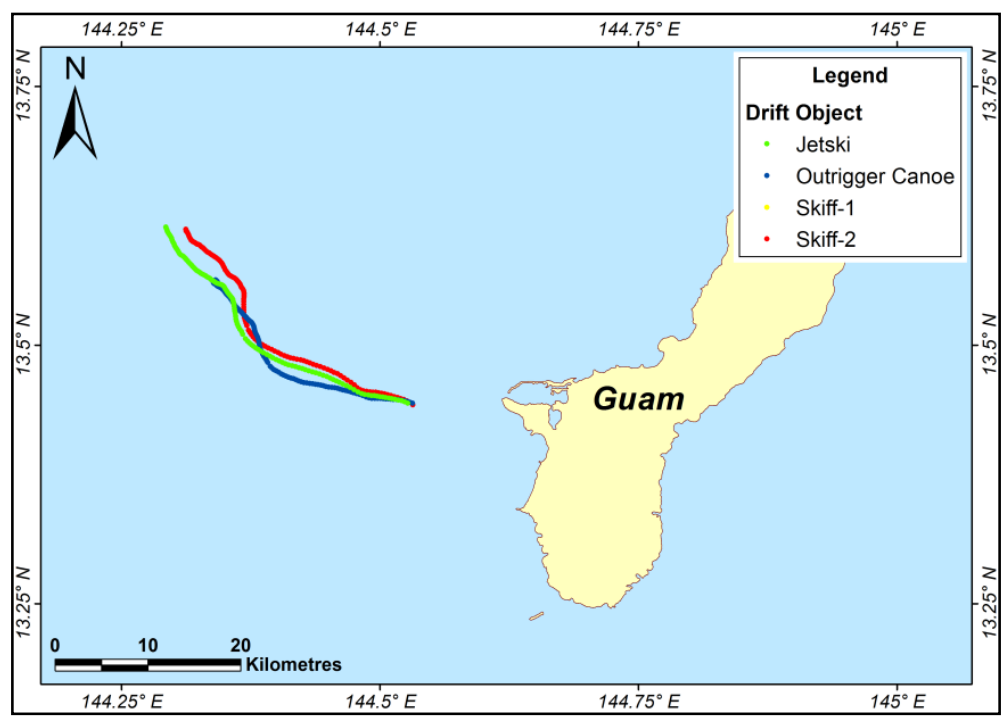

Figure 5. Guam drift runs: $12^{\text {th }}$ of June 2012 to $12^{\text {th }}$ of June 2012 


\subsection{Regression of Leeway Components}

A graphical representation of the linear regression for the 2-POB loading of the skiffs is shown in Figure 6 (constrained in red, unconstrained in blue) for the leeway speed (a), DWL (b) and CWL (c). The complete linear regression results for the leeway coefficients (leeway speed, CWL and DWL), and 95\% confidence level statistics of the skiff (under the four loadings tested), the outrigger canoe and PWC are summarised in Table 5 to Table 8.
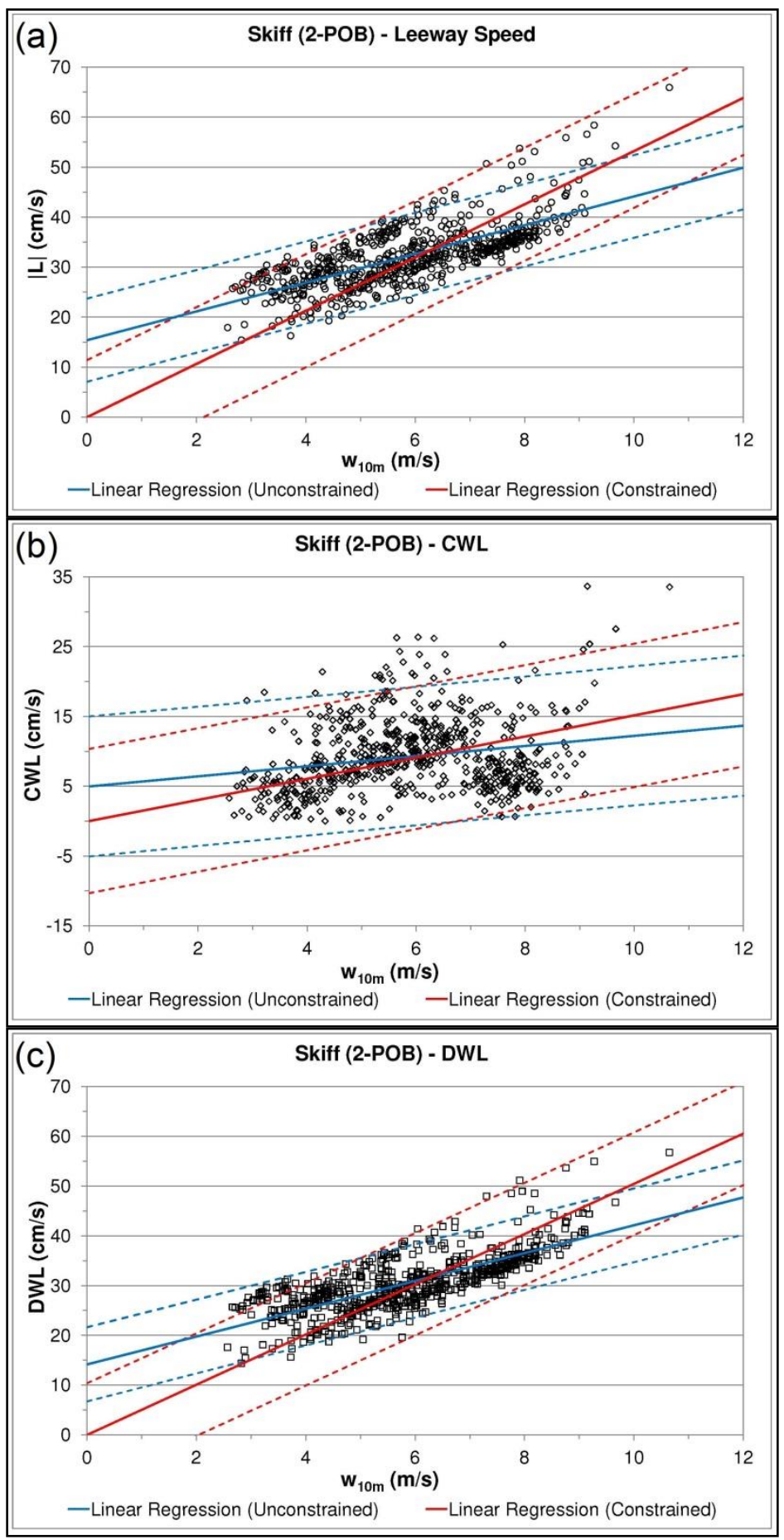

Figure 6. Leeway plots showing the linear regression of leeway components $(\mathrm{cm} / \mathrm{s})$ against the wind speed $(\mathrm{m} / \mathrm{s})$ adjusted to standard 10m reference height. (a) Leeway Speed, (b) Down Wind Leeway, and (c) Cross Wind Leeway - including both positive (left of down wind) and $\mathbf{- 1}$ times negative (right of down wind) components. Red solid line shows the constrained through zero linear regression, whilst Blue solid line 
shows the unconstrained linear regression. Dashed lines show the respective $95 \%$ confidence limits of the regressions.

Table 5. Unconstrained Linear Regression of Leeway Speed and Downwind Leeway Parameters

\begin{tabular}{|c|c|c|c|c|c|c|c|c|}
\hline \multirow[b]{2}{*}{ Drift Object } & \multicolumn{4}{|c|}{ Leeway Speed } & \multicolumn{4}{|c|}{ DWL } \\
\hline & $\begin{array}{c}\text { Slope } \\
(\%)\end{array}$ & $\begin{array}{c}\mathrm{Y} \\
(\mathrm{cm} / \mathrm{s}) \\
\end{array}$ & $\begin{array}{c}\text { Syx } \\
(\mathrm{cm} / \mathrm{s})\end{array}$ & $r^{2}$ & $\begin{array}{c}\text { Slope } \\
(\%)\end{array}$ & $\begin{array}{c}\mathrm{Y} \\
(\mathrm{cm} / \mathrm{s})\end{array}$ & $\begin{array}{c}\text { Syx } \\
(\mathrm{cm} / \mathrm{s})\end{array}$ & $r^{2}$ \\
\hline Panga w/1 POB & 3.28 & 15.72 & 1.59 & 0.71 & 3.89 & 11.90 & 1.69 & 0.75 \\
\hline Panga w/2 POB & 2.87 & 15.39 & 4.19 & 0.53 & 2.79 & 14.17 & 3.75 & 0.57 \\
\hline Panga w/4 POB & 3.80 & 6.51 & 1.97 & 0.92 & 2.92 & 8.25 & 2.15 & 0.86 \\
\hline Panga w/13 POB & 3.98 & 1.61 & 2.16 & 0.80 & 4.03 & 1.19 & 2.12 & 0.82 \\
\hline Outrigger canoe & 1.30 & 6.13 & 3.98 & 0.24 & 1.42 & 4.92 & 3.90 & 0.28 \\
\hline PWC & 3.46 & 4.99 & 3.31 & 0.67 & 3.59 & 3.41 & 3.20 & 0.72 \\
\hline
\end{tabular}

Table 6. Constrained through zero, Linear Regression of Leeway Speed and Downwind Leeway Parameters

\begin{tabular}{|c|c|c|c|c|c|c|c|c|}
\hline \multirow[b]{2}{*}{ Drift Object } & \multirow{2}{*}{$\begin{array}{c}\text { Range of } \\
\text { 10m Wind } \\
\text { Speed } \\
(\mathrm{m} / \mathrm{s})\end{array}$} & \multirow{2}{*}{$\begin{array}{c}\# \text { of } \\
10- \\
\text { minute } \\
\text { samples }\end{array}$} & \multicolumn{3}{|c|}{ Leeway Speed } & \multicolumn{3}{|c|}{ DWL } \\
\hline & & & $\begin{array}{c}\text { Slope } \\
(\%)\end{array}$ & $\begin{array}{c}\text { Syx } \\
(\mathrm{cm} / \mathrm{s})\end{array}$ & $r^{2}$ & $\begin{array}{c}\text { Slope } \\
(\%)\end{array}$ & $\begin{array}{c}\text { Syx } \\
(\mathrm{cm} / \mathrm{s})\end{array}$ & $r^{2}$ \\
\hline Panga w/1 POB & $1.4-4.7$ & 64 & 7.71 & 3.73 & -0.64 & 7.23 & 3.06 & 0.17 \\
\hline Panga w/2 POB & $2.6-10.6$ & 655 & 5.32 & 5.75 & 0.12 & 5.04 & 5.22 & 0.18 \\
\hline Panga w/4 POB & $1.6-11.9$ & 227 & 4.92 & 2.91 & 0.84 & 4.33 & 3.46 & 0.63 \\
\hline Panga w/13 POB & $2.0-5.2$ & 17 & 4.40 & 2.15 & 0.80 & 4.342 & 2.08 & 0.81 \\
\hline Outrigger canoe & $1.6-9.6$ & 307 & 2.40 & 4.44 & 0.05 & 2.30 & 4.21 & 0.16 \\
\hline PWC & $2.2-9.6$ & 181 & 4.24 & 3.49 & 0.65 & 4.12 & 3.28 & 0.70 \\
\hline
\end{tabular}

Table 7. Unconstrained Linear Regression of Crosswind Leeway Parameters

\begin{tabular}{lccccccccc}
\hline \hline Drift Object & \multicolumn{3}{c}{$+\mathrm{CWL}$} & \multicolumn{3}{c}{-CWL } & \multicolumn{3}{c}{$+\mathrm{CWL}-(-\mathrm{CWL})$} \\
& $\begin{array}{c}\text { Slope } \\
(\%)\end{array}$ & $\begin{array}{c}\mathrm{Y} \\
(\mathrm{cm} / \mathrm{s})\end{array}$ & $\begin{array}{c}\mathrm{Syx} \\
(\mathrm{cm} / \mathrm{s})\end{array}$ & $\begin{array}{c}\text { Slope } \\
(\%)\end{array}$ & $\begin{array}{c}\mathrm{Y} \\
(\mathrm{cm} / \mathrm{s})\end{array}$ & $\begin{array}{c}\text { Syx } \\
(\mathrm{cm} / \mathrm{s})\end{array}$ & $\begin{array}{c}\text { Slope } \\
(\%)\end{array}$ & $\begin{array}{c}\mathrm{Y} \\
(\mathrm{cm} / \mathrm{s})\end{array}$ & $\begin{array}{c}\text { Syx } \\
(\mathrm{cm} / \mathrm{s})\end{array}$ \\
\hline Panga w/1 POB & -0.66 & 11.29 & 2.73 & $\mathrm{n} / \mathrm{a}$ & $\mathrm{n} / \mathrm{a}$ & $\mathrm{n} / \mathrm{a}$ & $\mathrm{n} / \mathrm{a}$ & $\mathrm{n} / \mathrm{a}$ & $\mathrm{n} / \mathrm{a}$ \\
Panga w/2 POB & -0.20 & 11.27 & 5.60 & -2.28 & 3.36 & 2.71 & 0.73 & 4.97 & 5.05 \\
Panga w/4 POB & 2.86 & -3.81 & 3.60 & $\mathrm{n} / \mathrm{a}$ & $\mathrm{n} / \mathrm{a}$ & $\mathrm{n} / \mathrm{a}$ & $\mathrm{n} / \mathrm{a}$ & $\mathrm{n} / \mathrm{a}$ & $\mathrm{n} / \mathrm{a}$ \\
Panga w/13 POB & $\mathrm{n} / \mathrm{a}$ & $\mathrm{n} / \mathrm{a}$ & $\mathrm{n} / \mathrm{a}$ & 0.0009 & -2.49 & 1.41 & $\mathrm{n} / \mathrm{a}$ & $\mathrm{n} / \mathrm{a}$ & $\mathrm{n} / \mathrm{a}$ \\
Outrigger canoe & $\mathrm{n} / \mathrm{a}$ & $\mathrm{n} / \mathrm{a}$ & $\mathrm{n} / \mathrm{a}$ & $\mathrm{n} / \mathrm{a}$ & $\mathrm{n} / \mathrm{a}$ & $\mathrm{n} / \mathrm{a}$ & $\mathrm{n} / \mathrm{a}$ & $\mathrm{n} / \mathrm{a}$ & $\mathrm{n} / \mathrm{a}$ \\
PWC & $\mathrm{n} / \mathrm{a}$ & $\mathrm{n} / \mathrm{a}$ & $\mathrm{n} / \mathrm{a}$ & $\mathrm{n} / \mathrm{a}$ & $\mathrm{n} / \mathrm{a}$ & $\mathrm{n} / \mathrm{a}$ & $\mathrm{n} / \mathrm{a}$ & $\mathrm{n} / \mathrm{a}$ & $\mathrm{n} / \mathrm{a}$ \\
\hline
\end{tabular}

Table 8. Constrained through zero, Linear Regression of Crosswind Leeway Parameters

\begin{tabular}{|c|c|c|c|c|c|c|}
\hline \multirow[b]{2}{*}{ Drift Object } & \multicolumn{2}{|c|}{$+\mathrm{CWL}$} & \multicolumn{2}{|c|}{$-\mathrm{CWL}$} & \multicolumn{2}{|c|}{$+\mathrm{CWL}-(-\mathrm{CWL})$} \\
\hline & $\begin{array}{c}\text { Slope } \\
(\%)\end{array}$ & $\begin{array}{c}\text { Syx } \\
(\mathrm{cm} / \mathrm{s})\end{array}$ & $\begin{array}{c}\text { Slope } \\
(\%)\end{array}$ & $\begin{array}{c}\text { Syx } \\
(\mathrm{cm} / \mathrm{s})\end{array}$ & $\begin{array}{c}\text { Slope } \\
(\%)\end{array}$ & $\begin{array}{c}\text { Syx } \\
(\mathrm{cm} / \mathrm{s})\end{array}$ \\
\hline Panga w/1 POB & 2.52 & 3.63 & $\mathrm{n} / \mathrm{a}$ & $\mathrm{n} / \mathrm{a}$ & $\mathrm{n} / \mathrm{a}$ & $\mathrm{n} / \mathrm{a}$ \\
\hline Panga w/2 POB & 1.47 & 6.12 & -1.64 & 2.83 & 1.51 & 5.21 \\
\hline Panga w/4 POB & 2.21 & 3.80 & $\mathrm{n} / \mathrm{a}$ & $\mathrm{n} / \mathrm{a}$ & $\mathrm{n} / \mathrm{a}$ & $\mathrm{n} / \mathrm{a}$ \\
\hline Panga w/13 POB & $\mathrm{n} / \mathrm{a}$ & $\mathrm{n} / \mathrm{a}$ & -0.63 & 1.54 & $\mathrm{n} / \mathrm{a}$ & $\mathrm{n} / \mathrm{a}$ \\
\hline
\end{tabular}




\begin{tabular}{lllllll}
\hline \hline Outrigger canoe & 0.61 & 2.71 & -0.34 & 1.85 & 0.54 & 2.58 \\
PWC & 0.93 & 3.06 & -0.37 & 1.42 & 0.86 & 3.41 \\
\hline
\end{tabular}

\subsection{Jibing frequency}

The PVD of the five drift runs of the skiff with 2-POB loading is shown in Figure 7. Jibing events are more clearly visible in the zoomed figure (b), and are indicated by the four black arrows. A summary of the jibing frequency of all of the drift objects for all of the drift runs is presented in Table 9.
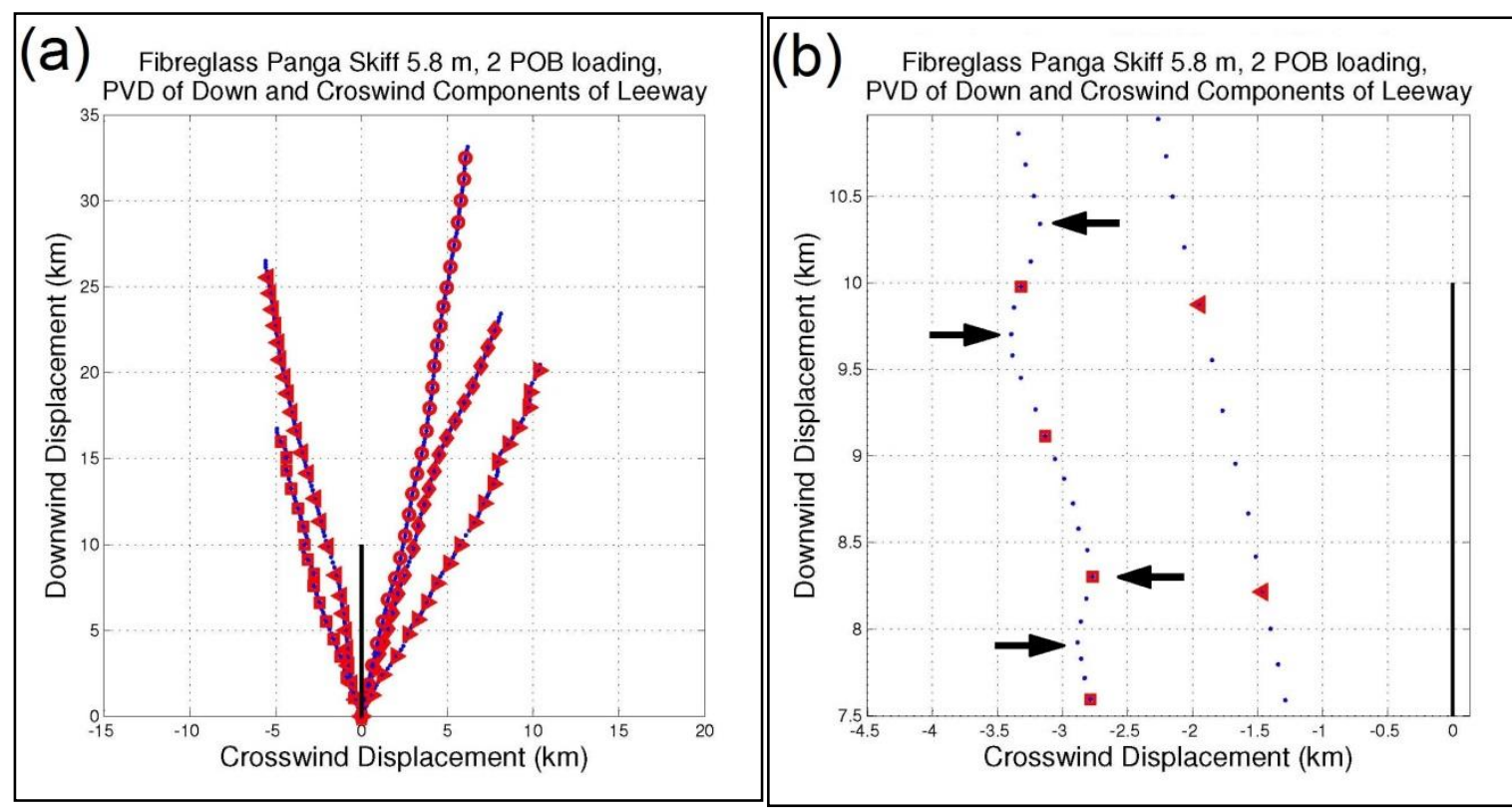

Figure 7. Progressive vector diagram (PVD) showing the downwind and crosswind leeway vector components of each drift run for the Fibreglass Skiff with 2-POB loading (a). Zoomed in view (b) shown for the left two tracks. The far left track indicates four of the six jibing events that occurred during that drift run (indicated by four black arrows). Downwind is shown as the black vertical line, with the wind blowing from the bottom of the figure towards the top.

Table 9. Jibing Frequency

\begin{tabular}{lcccc}
\hline \hline \multicolumn{1}{c}{ Drift Object } & $\begin{array}{c}\text { Range of } \\
\text { 10m }\end{array}$ & Wind Speed \\
$(\mathrm{m} / \mathrm{s})$ & $\begin{array}{c}\text { Hours:Minutes of } \\
\text { Samples }\end{array}$ & $\begin{array}{c}\text { CWL switches } \\
\text { (jibes) }\end{array}$ & $\begin{array}{c}\text { Frequency } \\
\text { Per hour } \\
(\%)\end{array}$ \\
\hline Panga w/1 POB & $1.4-4.7$ & $10: 40$ & 0 & 0 \\
Panga w/2 POB & $2.6-10.6$ & $109: 10$ & 6 & 5.5 \\
Panga w/4 POB & $1.6-11.9$ & $37: 50$ & 0 & 0 \\
Panga w/13 POB & $2.0-5.2$ & $02: 50$ & 0 & 0 \\
Panga total & $1.4-11.9$ & $160: 30$ & 6 & 3.7 \\
Outrigger canoe & $1.6-9.6$ & $51: 10$ & 4 & 7.8 \\
PWC & $2.2-9.6$ & $30: 10$ & 0 & 0 \\
\hline
\end{tabular}




\section{Discussion}

It was found that depending on the loading of the Panga skiffs, the constrained DWL may be up to $7.23 \%$ of the $10 \mathrm{~m}$ reference height wind speed, which is significantly higher (almost double) than the DWL previously recorded for similar sized / configured craft such as the $4.15 \mathrm{~m}$ Aluminium Skiff or the Cathedral hull - Boston Whaler, which have DWL coefficients of 3.95\% and 3.15\% respectively. Should the leeway coefficients of these similar craft be used as a proxy for the leeway coefficients of the Panga skiff, instead of the leeway coefficients calculated herein, the search areas would fall quite short of the actual location of the Panga skiff. The search object would then always be outside of the search area, and continue drifting further outside the search area as time goes on, thus giving a very low probability of a successful search outcome.

The outrigger canoe exhibited much lower leeway speed and DWL coefficients compared to the other craft tested (skiff and PWC), which was not surprising as the outrigger canoe floated deeper in the water compared to the skiff and PWC (approximately double the draft of the skiff and PWC). The combined effect of deeper draft as well as the additional drag of the outrigger would have contributed to retarding the leeway speed.

Whilst the downwind leeway component tends to have a directly linear relationship with the wind speed, the correlation between the crosswind leeway component and wind speed may not necessarily be linearly proportional to wind speed [5,7]. This is evident in the linear regression (using least squares line of best fit) of CWL to $\mathrm{W}_{10}$ wind speed for the results herein, and has often been the case with other leeway studies $[2,10,9]$. The $\mathrm{r}^{2}$ values are not shown in the CWL results tables as they are very low, and have been omitted for brevity. When there is insufficient CWL data to effectively regress against the wind speed, those results may have to be omitted, which was the case with various loadings of the Skiff, the PWC and the Outrigger canoe. The 2 POB loading of the skiff did return adequate data to perform the linear regression of CWL coefficients, due to the extended run times the skiff was loaded in this configuration (over 109 hours in total).

The leeway speed refers to the total leeway speed, or the combined DWL and CWL leeway vectors. This value is greater than the DWL, but not usually significantly greater, as the predominant direction of leeway speed is towards the downwind direction.

The $r^{2}$ value indicates how well the regression line fits the data. Values close to one indicate a perfect fit, whilst values close to zero indicate a poor fit. As the regression can be either unconstrained, or constrained through zero, an $r^{2}$ value can be given for both regressions for the same dataset. Typically, unconstrained $r^{2}$ values will be higher than those constrained, as the constraint through zero can artificially skew the data when it is forced to pass through zero.

The rate of expansion of the search area is related to the uncertainty of the drift characteristics of the object in question. The $\mathrm{S}_{\mathrm{yx}}$ error term used in many of the stochastic search and rescue models available controls this level of uncertainty in the object's drift, thus a larger $S_{y x}$ term will result in a more rapidly expanding search area. Whilst a large search area has a higher probability of containment (POC), whereby it is more likely that the 
search object will remain within the search area; this is balanced by the availability of resources to adequately search that area. The 95\% prediction limits (indicated by the dashed lines on Figure 6) may vary between the unconstrained and constrained analysis of the leeway coefficients. An unconstrained regression will generally give tighter prediction limits compared to the constrained through zero regression of the same data, as indicated by the data in Table 5 to Table 8 . The $95 \%$ prediction limits are directly related to the standard error $\left(\mathrm{S}_{\mathrm{yx}}\right)$, and larger $\mathrm{S}_{\mathrm{yx}}$ values indicate larger or wider $95 \%$ prediction limits.

The jibing frequency indicates how often the object changes its CWL sign as a percentage per hour. Jibing is a nautical term which refers to when a yacht changes tack (course) and passes its stern through the eye of the wind. Allen [5] introduced the use of jibing when defining the search area for objects adrift at sea, and its use in SAR modelling. Modelling the frequency of jibing is can be difficult due to the complex dynamics involved with modelling the flow of fluids around a drifting object, especially when that object is at the interface between two fluids of significantly different densities (water/air interface). It is proposed that rapid shifts in environmental forcing, such as a change in wind strength and direction may cause jibing to occur. There are currently no statistical models available to determine the jibing frequency of an object; however it was indicated by Allen [5] that past observations have yielded a jibing frequency in the range of $3 \%$ to $7 \%$ per hour, which may be used as a guideline for current and future studies. The skiff only exhibited jibing on the runs when it was under the 2-POB loading, with a jibing frequency of 5.5\% which is within the range suggested by Allen [5]. The outrigger canoe jibed on several of its runs, returning a higher jibing frequency of $7.8 \%$ which is slightly larger than the aforementioned suggested upper limit of $7 \%$. The PWC did not exhibit any jibing events. Longer run times where the drift object is allowed to drift without being interfered with are required to effectively ascertain the jibing frequency of a drift object, and as the jibing events are relatively rare - a larger number of samples are required to encapsulate these infrequent events.

During the first deployment, to the west of Chuuk (FSM), all of the drift objects tracked in a west to north westerly direction throughout the 5-day deployment duration (Figure 3). The skiffs were drifted for approximately 24 hour intervals, alternating between Skiff- 1 and Skiff-2 over the 5-days. The other craft (PWC and outrigger canoe) were drifted during daylight hours only over the 5-days. The westerly drift exhibited by all craft during this deployment was attributable to the westerly surface currents which are predominately driven by the easterly trade winds.

The short drift tracks shown in Figure 4 depict the shorter duration deployment ( 11hrs) nearby to Puluwat, FSM. These tracks all take a south westerly direction, with the skiff tracks being the longest (as they drifted the fastest) whilst the outrigger canoe track was the shortest (due to its slower drift). The winds and weather was calm during this run, with maximum wind speeds of $4.7 \mathrm{~m} / \mathrm{s}(9.1 \mathrm{kts})$. This was the only run which took a southerly direction (albeit still with a westerly component) whilst the other deployments near Chuuk and Guam both tracked towards the north west.

Figure 5 shows the drift path of the objects when deployed off the western coast of Guam, approximately $9.2 \mathrm{~km}$ west of Apra Harbour. The drift objects took a north westward drift trajectory for the first $\sim 9$ hours of the run, before changing direction to drift towards the north for approximately 5 hours, and then altering course again 
back towards the north west for the remainder of the drift run. All three drift objects took similar trajectories, which indicate that a wind direction change came through at the times that the objects each changed their courses, and that wind change was the driving force for the objects to change course. This was confirmed in the wind records from the weather station aboard the skiff, which showed that the wind changing direction, blowing predominately from the east, before swinging towards the south east, and then back towards the east south east. The skiff and PWC did not record any jibing events during this run, however the outrigger canoe jibed twice, and both times it was observed to jibe there was a change in both wind intensity and direction (recorded by the weather station aboard the skiff), indicating the wind shift caused the outrigger canoe to jibe. Both the skiff and the PWC drifted in a very similar fashion, both finishing within $\sim 2 \mathrm{~km}$ of each other, whilst there was a greater separation between these two drift objects and the outrigger canoe, which drifted much slower, and finished the drift run approximately $\sim 7 \mathrm{~km}$ behind the other two craft. Whilst it appears that the changes in direction occur earlier for the outrigger canoe (closer to the start of the drift path) compared to the other two drift objects, it is in fact due to the outrigger canoe moving slower, and hence lagging behind the other two drift objects which were able to drift further before the wind change came through, and hence all three objects were subjected to the wind change event at essentially the same time, however their positions slightly varied spatially.

\section{Conclusions / Recommendations}

The methodology undertaken during the leeway field tests to determine the standard leeway coefficients of three common tropical pacific island craft; a 5.8m fibreglass skiff (Panga), a 5.9m outrigger canoe, and a two person sit down PWC, has been described herein. Data was successfully recovered for each of the three drift objects, and their leeway coefficients were effectively calculated utilising currently recognised methods, in line with other leeway studies undertaken.

It is recommended that the three drift objects (and their associated leeway coefficients) are added to the leeway databases for search and rescue drift objects, and implemented into the various search and rescue models used internationally. Already the leeway data from these three drift objects has been integrated into the USCG SAROPS search and rescue drift forecast system and has been used during several SAR incidents within the Tropical Pacific region with successful results. The leeway coefficients calculated herein are currently being implemented into the Australian and New Zealand maritime SAR systems.

It is imperative that continued research into the leeway of common search objects is undertaken to ensure that the databases of leeway drift objects is as up to date and complete as possible. Revisiting common search objects (e.g. PIW) that have been studied in the past, with new methods and techniques (direct method) and more advanced instrumentation will lead to a better description of their drift characteristics and minimisation of the drift error, and hence reduction in the search area sizes required to adequately contain these objects. It is important that there are regional leeway databases of common craft which are specific to an area, and that these are updated accordingly. 


\section{Acknowledgements}

This work was financially supported by; the US Coast Guard Office of Search and Rescue, US Coast Guard Academy, US Coast Guard District Fourteen, Griffith University and the Australian Research Council's Linkage Projects funding scheme LP0991159. The authors would like to acknowledge the assistance received the Coast Guard Academy waterfront personnel, RJ Burns; Cadets Arnold, Kennedy, and Byrd in preparation of the PWC and the personnel at Coast Guard Sector Guam. We would also like to thank the officers and crew of the USCGC SEQUOIA for their outstanding professionalism and good humour throughout the cruise. We express our sincere appreciation to the reviewers of this paper for their constructive recommendations.

\section{References}

[1] Ø. Breivik, A. A. Allen, C. Maisondieu and M. Olagnon, Advances in Search and Rescue at Sea, Ocean. Dyn. 63 (2013) 83-88.

[2] Ø. Breivik, A. A. Allen, C. Maisondieu and J.-C. Roth, Wind-induced drift of objects at sea: The leeway field method, Appl. Ocean. Res. 33 (2011) 100-109.

[3] B. Hackett, $\varnothing$. Breivik and C. Wettre, Forecasting the Drift of Objects and Substances in the Ocean, in: E.

P. Chassignet and J. Verron (Eds.), Ocean Weather Forecasting - An Integrated View of Oceanography, Springer, Dordrecht, 2006, pp. 507-523.

[4] Ø. Breivik and A. A. Allen, An operational search and rescue model for the Norwegian Sea and the North Sea, J. Marine Syst. 69 (2008) 99-113.

[5] A. A. Allen, Leeway Divergence, U.S. Coast Guard, Washington DC, 2005.

[6] F. Pingree, Forethoughts on Rubber Rafts, 1944.

[7] A. A. Allen and J. V. Plourde, Review of Leeway: Field Experiments and Implementation, U.S. Coast Guard, Washington DC, 1999.

[8] P. Daniel, G. Jan, F. Cabioc'h, Y. Landau and E. Loiseau, Drift Modelling of Cargo Containers, Spill Sci. Technol. B. 7 (2002) 279-288.

[9] A. A. Allen, J.-C. Roth, C. Maisondieu, Ø. Breivik and B. Forest, Field Determination of the Leeway of Drifting Objects, Norwegian Meteorological Institute, Oslo, 2010.

[10] Ø. Breivik, A. A. Allen, C. Maisondieu, J.C. Roth and B. Forest, The Leeway of Shipping Containers at Different Immersion Levels, Ocean. Dyn. 62 (2012) 741-752.

[11] Austrailan Maritime Safety Authority, National Search and Rescue Manual 2011 Version 11, 2011.

[Online]. Available:

http://natsar.amsa.gov.au/Manuals/Search_and_Rescue_Manual/documents/NATSARMAN2011.pdf. [Accessed 19 July 2013].

[12] F. J. Davidson, A. A. Allen, G. B. Brassington, Ø. Breivik, P. Daniel, M. Kamachi, S. Sato, B. King, F. Lefevre, M. Sutton and H. Kaneko, Applications of GODAE Ocean Current Forecasts to Search and Rescue and Ship Routing, Ocean. 223 (2009) 176-181.

[13] T. M. Kratzke, L. D. Stone and J. R. Frost, Search and Rescue Optimal Planning System, in: IEEE 
Proceedings of the 13 International Conference on Information Fusion, Edinburgh, 2010.

[14] M. L. Spaulding and E. Howlett, Application of SARMAP to Estimate Probable Search Area for Objects Lost at Sea, Mar. Technol. Soc. J. 302 (1996) 17-25.

[15] M. L. Spaulding, T. Isaji, P. Hall and A. A. Allen, A Hierarchy of Stochastic Particle Models for Search and Rescue (SAR): Application to Predict Surface Drifter Trajectories using HF radar Current Forcing, J. Mar. Environ. Eng. 83 (2006) 181-214.

[16] Canadian Coast Guard, Canadian Coast Guard College CANSARP Development Group Web Site,CANSARP User Manual, 2009. [Online]. Available:

http://loki.cgc.gc.ca/cansarp/cansarpmanualsept1609.pdf. [Accessed 6 November 2013].

[17] P. Daniel, F. Marty, P. Josse, C. Skandrani and R. Benshila, Improvement of Drift Calculation in MOTHY Operational Oil Spill Prediciton System, in: 2003 International Oil Spill Conference, Vancouver, 2003.

[18] A. A. Allen, B. A. Brushett and V. C. Futch, Results from the Guam/Chuuk/Puluwat 2012 Leeway Field Tests, Griffith University, Gold Coast, 2013.

[19] S. D. Smith, Coefficients for Sea Surface Wind Stress, Heat Flux, and Wind Profiles, J. Geophys. Res. 93 (1988) 15467-15472. 